No. 3(60), 2019, pp. 211-226

https://doi.org/10.12797/Politeja.16.2019.60.14

\author{
Mercè BALLESPÍ VILLAGRASA (D) \\ Aula de Teatro de Lleida / Universidad de Lleida \\ merceballespi@gmail.com
}

\title{
EL TALLER DE TEATRO: \\ UN RETO PARA EL APRENDIZAJE ELE EN SINOHABLANTES
}

ABSTRACT Theatre Workshop: A Challenge for Chinese Students Learning Spanish as a Second or a Foreign Language

Based on a specific teaching experience, this paper reveals some specific factors for learning language and Spanish culture during the process of creating a theatre workshop with a group of students from China. Since 2013, the University of Lleida (Spain) through the Diploma of Hispanic Studies (DEH) and the collaboration of Aula Municipal de Teatre of Lleida has taught theatre workshops previously with public presentation conducted entirely in Spanish, with Chinese students who not only want linguistic immersion in Hispanic environment, but also cultural. The advantages and the results obtained are detailed thanks to the use of dramatic expression in the learning of Spanish as a Foreign Language (ELE) as well as the difficulties, the didactics and the methodology used during four academic courses with 75 Chinese students.

Key words: theatre, Spanish as a Foreign Language, Chinese students, drama teaching, Hispanic Studies 


\section{EL AULA MUNICIPAL DE TEATRO DE LLEIDA}

En territorio español las escuelas municipales responden a una necesidad de los municipios para la enseñanza artística con carácter no formal. Muchas son las muestras de escuelas municipales de teatro, música, danza y bellas artes que tuvieron su proliferación con el inicio de la democracia, una vez superada la dictadura de Francisco Franco a partir de 1975, con una visión global de lo que serían las futuras políticas culturales.

En el caso de la ciudad de Lleida su ámbito cultural únicamente recaía en la Escuela de Música, pero a partir del 1979 se conformó la Escuela Municipal de Bellas Artes y en 1981 la de Teatro, todas ellas nacidas para cubrir necesidades culturales y como núcleos de agitación y sensibilización artística.

El Aula Municipal de Teatro de Lleida es una institución destinada a la enseñanza del teatro tanto para aquellas personas que quieren disfrutar del teatro por placer como para aquellas que hacen del teatro su profesión. A lo largo de sus 37 años de historia la escuela se ha convertido en un referente de la pedagogía teatral en todo el territorio español.

La escuela ofrece formación teatral para niños y niñas, para jóvenes, personas adultas y cursos específicos vinculados a la enseñanza de las artes escénicas. Desde 2015 también se imparten los estudios de Ciclo Formativo de Grado Superior en Técnicas de Actuación Teatral, una nueva formación de Título Propio de la Generalitat de Cataluña ${ }^{1}$ que permite profesionalizar el oficio de actor y actriz. Ofrece también respuesta a numerosos cursos de artes escénicas específicos demandados por otras instituciones. Es en este último punto donde se inscriben los cursos/talleres de teatro para la Universidad de Lleida.

Actualmente las cifras de alumnado matriculado (a partir de 3 años) superan los 2000 alumnos y el equipo docente está compuesto por 40 profesionales, tanto de dedicación exclusiva como puntual ${ }^{2}$.

El libro Aula, 25 anys, que se publicó con motivo del $25^{\circ}$ aniversario de la entidad, recoge las impresiones de gran parte de los protagonistas que consolidaron e hicieron crecer la escuela. A destacar su primer director, Marcellí Borrell, que a lo largo de 21 años impulsó y consolidó el centro. Las siguientes direcciones: Mercè Ballespí del 2002 al 2009; Antonio Gómez del 2009 al 2017 y Mireia Teixidó en la actualidad han expandido la metodología creada y han desarrollado un proceso de expansión y visibilidad mediante, entre otros, 2 proyectos de compañías teatrales con alumnado.

Así La Inestable 21, compañía juvenil del Aula, nace en el año 2001 y La Petiestable 12, la compañía infantil, en el 2009 como un proyecto educativo pre-profesional del Aula. A lo largo de estos años ha permitido a los jóvenes entre 13 y 20 años y a los

Título propio de la Generalitat de Cataluña recogido en el Decreto 85/2015 del 2 de junio, con efectos profesionales. La concepción de esta formación oficial se debe a la demanda de la Asociación de Escuelas Catalanas de Teatro (ACET) donde el Aula de Teatro de Lleida tuvo una fuerte implicación, tanto en la confección del currículum como en su implantación en Cataluña.

2 Para más información: Aula de Teatre de Lleida, [online] http://aulateatre.com/es/. 
niños de 7 a 12 años vivir una experiencia que les ha llevado por España y Europa en innumerables teatros, festivales y certámenes, mostrando espectáculos de un gran nivel artístico.

Los proyectos de crear compañía contienen, en líneas generales, un marco educativo y profesional que tiene por objetivo hacer vivir a jóvenes y niños la experiencia de formar parte de una compañía 'profesional' de teatro. Formar parte de las compañías permite participar del proceso creativo, crear una producción teatral y realizar una gira durante un año con ese espectáculo.

La reacción del público al ver, escuchar y sentir los 'pequeños-grandes' actores y actrices, es de sorpresa al principio y de reconocimiento al finalizar la función. Ambas compañías son la demostración de que es posible dar voz real a los menores, ya que ellos serán nuestro futuro. Acostumbrados a ser receptores de cultura, se convierten en protagonistas indiscutibles, en agentes activos de la sociedad.

Datos como los más de 60 premios y reconocimientos a nivel nacional, que el 40 por ciento del alumnado participante a lo largo de 15 años acaban cursando estudios superiores de teatro, o que el $27 \%$ se dedican profesionalmente al teatro, avalan el proyecto.

Uno de los pilares fundamentales de la escuela es la pasión por las artes escénicas, el ambiente distendido, voluntarioso y disciplinado que se respira motiva a la creación teatral desde una visión ecléctica, transversal y social de la experimentación artística.

\section{DIPLOMA DE ESTUDIOS HISPÁNICOS ${ }^{3}$ DE LA UNIVERSIDAD DE LLEIDA}

La Universidad de Lleida tiene sus orígenes en 1300 con la fundación por parte del Rey Jaime II y el Papa Bonifacio VIII del Estudio General de Lleida ${ }^{4}$. Actualmente engloba cuatro campus universitarios con sus respectivas Escuelas y Facultades, 7 centros propios y 3 adscritos. Según el estudio de Ránquines de las Universidades Españolas ISSUE $2015^{5}$ es la cuarta mejor universidad de España en docencia y la séptima en investigación.

En referencia al Diploma de Estudios Hispánicos (DEH) en 2003 se iniciaron las primeras conversaciones con la Universidad de Estudios Extranjeros de Tianjin (República Popular China) que dieron sus frutos con el primer convenio firmado el 1 de julio de 2005 entre el entonces Rector de la UdL, Joan Viñas, y el Rector de Tianjin Foreign Studies University, Xiu Gang. En octubre de 2006 se realizó el primer curso del DEH con alumnado íntegramente chino. Desde entonces las promociones de alumnos procedentes de China no han frenado y actualmente los convenios se han ampliado con la Binhai School of Foreign Affairs (distrito de Binhai/Dagang, en Tianjin),

\footnotetext{
3 Información actualitzada sobre el Diploma de Estudios Hispánicos de la Universidad de Lleida en http://www.filcef.udl.cat/es/estudis/diploma-destudis-hispanics/.

4 Para ampliar información consultar en http://www.udl.es/ca/udl/historia/.

5 Indicadores sintéticos del Sistema Universitario Español en http://www.u-ranking.es/analisis.php.
} 
Nankai University, y cerca de Shanghai la Changzhou University y la Soozhow University. Todo ello ha propiciado que más de 350 alumnos hayan conseguido su diploma con éxito en una inmersión académica y cultural durante un año en la ciudad de Lleida.

El DEH (60 créditos) está dirigido a estudiantes que han aprobado 2 años de estudios universitarios en su universidad de origen y están cursando su tercer año de estudios.

El Plan de Estudios inicial del DEH se vio modificado a raíz que el Dr. Javier Terrado, en aquel momento jefe del Departamento de Filología Clásica, Francesa e Hispánica de la Facultad de Letras, complementó su asignatura con lecturas en voz alta de la pieza teatral La barca sin pescador de Alejandro Casona, con el fin de mejorar la pronunciación y la entonación castellana de sus alumnos extranjeros. Este hecho, de resultados satisfactorios, propició la incorporación de una nueva materia en el Plan de Estudios: Teatro y Expresividad con una carga lectiva de 30 horas. La docencia de esta nueva materia fue asumida como Taller de Teatro, equivalente a 3 créditos, por el profesorado de español como lengua extranjera (ELE).

Es a partir del 2013 que la Universidad de Lleida establece la colaboración de el Aula Municipal de Teatro de la ciudad para una docencia con garantías de profesionalidad escénica para esta materia tan concreta de Teatro y Expresividad.

\section{TALLERES DE TEATRO REALIZADOS EN EL DEH (2013-2017)}

A lo largo de esta específica experiencia académico-teatral de español para sinohablantes con nula experiencia teatral previa se han realizado cuatro talleres finales al alumnado del Diploma de Estudios Hispánicos de la UdL, estos son:

Curso 2013-2014 Leyendas Españolas

Curso 2014-2015 El Lazarillo de Tormes

Curso 2015-2016 Don Quijote, de Miguel de Cervantes

Curso 2016-2017 Método Grönholm de Jordi Galcerán

Seguidamente se pasará una breve explicación y algunos de los datos recogidos de cada uno de ellos para ofrecer una visión detallada de las particularidades de cada curso académico.

\subsection{Curso 2013-2014: Leyendas Españolas, pieza de creación}

Taller de teatro planteado a partir de los conocimientos culturales que, a priori, poseían los 23 alumnos del grupo. Las inquietudes del alumnado hicieron que trabajásemos con material poético (poemas de Pablo Neruda), algunas leyendas e historias referidas a la cultura hispánica y muchas letras de canciones de música española que habitualmente escuchan para estar más en contacto con el idioma. Esta aportación musical dio un aire muy fresco y dinámico al taller, haciendo, ellos mismos una coreografía grupal final. 
El material de La Leyenda de San Eloi sirvió para explicar la religión católica y el concepto de milagro. Observando en las letras de las canciones que una de las inquietudes más habituales es el amor imposible, la leyenda de origen aragonés de Los amantes de Teruel sirvió para dar la visión romántica al taller.

Algunos de los alumnos manifestaron deseos sobre temática de misterio, de suspense, de la vida después de la muerte y por este motivo se facilitó, por parte de la profesora, la Leyenda de Navidad de Carlos Ruiz Zafón que respondía en gran medida a la temática deseada.

Una vez organizado dramatúrgicamente todo el material textual, creativo e interpretativo el taller se presentó al público (comunidad educativa de ambas instituciones) y público en general en mayo 2014 en el Teatro Municipal del Escorxador, en la ciudad de Lleida.

\subsection{Curso 2014-2015 El Lazarillo de Tormes, de adaptación propia}

Para el segundo taller la propuesta dramática fue La Vida del Lazarillo de Tormes y de sus fortunas y adversidades, símbolo de la novela autobiográfica y picaresca. El tratamiento en primera persona permitió dar a la pieza el hilo conductor del protagonista (que se iba cambiando de actor y actriz según la escena) y hacía inmersión de los alumnos en los estamentos, las jerarquías y las costumbres de la España del siglo XVI.

La dramaturgia libre permitió dar a los 21 alumnos que componían el taller una visión vital de el personaje Lazarillo: Orígenes humildes que le dan nombre, episodios con el ciego (jarra de vino y cruzar el río), episodio con el clérigo (el baúl y la llave), episodio con su amo escudero, y episodios grupales con ambientación y simbología propia de la época.

El Taller Lazarillo de Tormes fue estrenado en la sala 2 del Teatro Escorxador de Lleida el 13 de mayo del 2015.

\subsection{Curso 2015-2016: Don Quijote, de adaptación propia}

El leitmotiv del curso fue la conmemoración del 400 aniversario de la muerte de Miguel de Cervantes y por tanto la propuesta teatral se centró en la temática y ambientación de la obra más emblemática de la literatura hispánica: El ingenioso hidalgo Don Quijote de La Mancha. La Universidad de Lleida celebró la Semana de las Letras Hispánicas ${ }^{6}$, entre otros, con un homenaje a los 10 años del Diploma de Estudios Hispánicos, que ya contaba con más de 230 alumnos chinos en su paso por estos estudios.

6 Semana de las Letras Hispánicas, del 19 al 23 de abril del 2016. La Universidad de Lleida realizó conferencias, mesas redondas, exposición paralela y participación gracias a la implicación de organizaciones como: Diploma de Estudios Hispánicos, Departamento de Filología Clásica, Francesa e Hispánica, Cátedra de Estudios Asiáticos, Centro de Formación Continua Facultad de Letras, Vicerrectorado de Actividades Culturales y Proyección Universitaria, Vicerrectorado de Docencia y Vicerrectorado de Relaciones Internacionales entre otros. Para más información: http://www.filcef.udl.cat/es/activitats/ pagina-1/. 
Dada la dificultad comprensiva del texto se optó por una versión adaptada a jóvenes y se propuso al grupo pequeñas dramatizaciones de los capítulos de la obra cervantina que más les llamaron la atención. La participación de los estudiantes fue la clave para escoger los capítulos centrales, el grupo decidía qué era más interesante. Una vez realizada la primera criba, las dramatizaciones escogidas fueron trasladadas a texto dramático con diálogos teatrales, algunos de ellos, realizados por ellos mismos.

En este taller se mantuvo al personaje protagonista a lo largo de toda la obra, se añadió la presencia del personaje Cervantes y se utilizó la técnica interpretativa del sistema comodín ${ }^{7}$ desarrollada por Augusto Boal de multiplicar ciertos personajes, como el de juglares, para el bien de la acción dramática. Los capítulos escogidos sitúan a Don Quijote en su casa (inicio de su locura y regreso para su muerte), en dos ventas, en las galeras y en exteriores como la batalla de los leones y la emblemática contra molinos de viento.

El Taller Don Quijote fue estrenado en la Sala 2 del Teatro Escorxador de Lleida el 19 de mayo de 2016.

\subsection{Curso 2016-2017 El Método Grönholm de Jordi Galcerán}

El grupo de estudiantes del DEH era muy numeroso y la Universidad optó por mantener la materia con uno de los subgrupos. Con los 13 alumnos y alumnas escogidos se hizo una primera presentación pública al finalizar el primer trimestre basada en anécdotas personales en su inmersión cultural en un nuevo país. Se emplearon las 10 primeras sesiones a este fin resultando una presentación muy fresca donde resaltaba la soltura con el idioma y la adecuación expresiva.

A partir de enero se trabajó con el texto de El Método Grönholm de Jordi Galcerán con una adaptación para 13 personajes y con la peculiaridad de poder escoger el final de la pieza. A nivel de dramaturgia se suavizó la carga psicológica de los 4 personajes iniciales para dar más énfasis a la superación de pruebas grupales, como juegos de rol o coreografías, con el fin de conseguir un cargo directivo en una multinacional.

El Taller de Teatro El Método fue estrenado en Teatro Julieta Agustí de Lleida el 25 mayo de 2017.

\section{APRENDIZAJE LE POR MEDIO DE LA EXPRESIÓN DRAMÁTICA}

El porqué utilizar la expresión teatral en el ámbito de ELE viene justificado por los innumerables beneficios que el aprendizaje en artes escénicas otorga a los estudiantes. Como justificación me remito al estudio DICE $^{8}$ (Drama Improves Competences in Education), investigación llevada a cabo por expertos de teatro en la educación, en doce

Para más información sobre esta técnica interpretativa me remito a Teatro del Oprimido, obra de referencia de Augusto Boal.

8 El estudio completo de la investigación puede consultarse en http://www.dramanetwork.eu/educational_drama.html. 
países y con una muestra de cerca de 5000 estudiantes, donde se comprueba cómo las artes escénicas contribuyen decisivamente al desarrollo de cinco competencias básicas, estas son:

- La comunicación lingüística

- La capacidad de aprender a aprender

- Las habilidades interpersonales, interculturales y sociales

- El sentido de la iniciativa y el emprendimiento

- La expresión cultural

Así pues, la expresión teatral favorece en gran medida estas competencias básicas y no solo con resultados inmediatos, sino que también a medio y largo término se puede apreciar este tipo de aprendizaje para el desarrollo integral de las personas y, evidentemente, abriendo la perspectiva en ámbitos no exclusivamente académicos. La comunicación se amplía también en la perspectiva del lenguaje no verbal, es todo el cuerpo, los gestos, los movimientos y la expresividad personal los factores clave para una comunicación real, global y efectiva. Las habilidades comunicativas se ponen de relieve cuando las dinámicas propuestas permiten un grado de socialización y empatía con el resto de participantes que difícilmente otro tipo de disciplinas académicas consiguen con metodologías convencionales. El contraste entre la diversidad cultural solo puede entenderse mediante el respeto, buscando diferencias y similitudes, que no hacen sino acercar desde puntos aparentemente dispares a los participantes. De esta forma se llega a un entendimiento entre personas que supera toda reticencia cultural. Un acercamiento desde la emoción, el sentimiento, la humanidad enriquece el contacto entre culturas, potenciando habilidades interculturales y sociales.

El desarrollo del sentido de la iniciativa en el colectivo oriental con el que se ha trabajado se plasma en las actitudes frente a propuestas no dirigidas. Realmente el sentido de la iniciativa es un punto delicado ya que habitualmente factores negativos como la timidez, la inseguridad o la vergüenza frenan las posibilidades de actuar de manera creativa, factor esencial para el emprendimiento. Justamente uno de los objetivos por el cual están estudiando español y concretamente el DEH es un futuro profesional donde puedan ejercer como profesores de español, traductores, guías turísticos, iniciativas empresariales entre España y China, así como otras profesiones vinculantes. Por lo tanto, el objetivo final de muchos de los participantes es trabajar en ámbitos que requieren alto sentido de emprendimiento, sin que se den cuenta que su actitud no refleja en absoluto su deseo. Una de las actividades que mejores resultados ofrece para solucionar este distanciamiento entre la realidad personal y la percepción de ésta son los juegos sensoriales y de confianza. Por ejemplo, con los ojos vendados confiar en un compañero/guía en diversos recorridos para finalmente saltar desde cierta altura para ser acogido suavemente por el grupo. No todos los alumnos se atreven con la última parte del ejercicio, ya que requiere mucha confianza personal y con el grupo, pero sí que se aprende a gestionar inseguridades y miedos intangibles. Otro ejercicio muy interesante es el juego simbólico con los oficios que, a priori, desean ejercer en el futuro. El juego simbólico es hacer 'como si' fueran un personaje concreto, 'como si' ejercieran una profesión determinada, etc... Esta propuesta requiere mucha implicación del estudiante y refleja, no solo sus 
deseos delante de otras personas - expresión muy íntima en la cultura china - sino también muchas carencias en habilidades expresivas y en la concreción de su visión de un oficio determinado. Este choque de realidades mediante ejercicios de confianza o juegos simbólicos les demuestra que la expresión dramática puede ser, también, un buen ensayo para focalizar su futuro profesional.

\subsection{El reto}

Recoger las necesidades de inmersión lingüística y cultural de los grupos de estudiantes del Diploma de Estudios Hispánicos de la Universidad de Lleida (DEH) e impartir la asignatura de Teatro y Expresividad de 3 créditos concretándola en la forma de taller de teatro con representación pública final.

Lograr una experiencia educativa integradora de lenguajes expresivos, donde prima el proceso ${ }^{9}$ y se potencian habilidades de comunicación verbal y no verbal, de autoestima, de empoderamiento y de trabajo en equipo. Todo ello con alumnado en su totalidad sinohablante y sin experiencia dramática anterior.

\subsection{Dificultades}

A priori la dificultad más evidente para la docencia de la materia Teatro y Expresividad del DEH con alumnado íntegramente sinohablante es por una parte el desconocimiento de los estudiantes de lo que es el Teatro y por otra la ausencia de expresividad en el entorno social de la cultura china. La cortesía y el respeto que los alumnos profesan a los profesores no facilita que la comunicación sea fluida, no se dan indicadores expresivos de ninguna índole para adecuar un canal efectivo de enseñanza-aprendizaje. Y justamente el reto de la materia es potenciar la expresividad de cada estudiante y realizar un taller de teatro.

Además de las dificultades en el aprendizaje de una lengua extranjera como el español tan dispar de su lengua materna también se debe tener en cuenta las interferencias provocadas por la lengua extranjera de referencia que estos grupos poseen, el inglés, tal y como detalla en su artículo J.M. Santos ${ }^{10}$. La lengua extranjera por excelencia en la República China es el inglés y este dato debe ser tomado como una oportunidad de paralelismo y de obertura de perspectiva. Pueden darse interferencias reales que los docentes de las dos lenguas deben aprovechar. Por proximidad fonética, morfológica, sintáctica, léxica y cultural el alumnado sinohablante establece paralelismos entre las dos lenguas que le son realmente útiles. Indiscutiblemente el inglés, será su base lingüística para el aprendizaje del español. Es por este motivo que ciertos errores, como por ejemplo el uso inadecuado de los verbos ser/estar resulta muy evidente ya que ni en chino ni en inglés se da esta diferenciación verbal. Lo mismo ocurre con los adjetivos porque tanto en chino

$9 \mathrm{Al}$ modo que desarrolla Isabel Tejerina para niños y adolescentes en "El juego dramático como herramienta de la educación intercultural”, Primeras noticias. Revista de literatura, no. 244 (2009), pp. 53-59.

10 J.M. Santos Rovira, "Dificultades específicas de los sinohablantes aprendices de español", Estudios de Linguística Aplicada, vol. 29, no. 54 (2011), pp. 161-176. 
como en inglés van delante del sustantivo. Tendremos que situar así en un contexto único los errores habituales de género y de las conjugaciones de los tiempos verbales. Otra apreciación que cabe citar para enmarcar las dificultades sintácticas es que habitualmente las oraciones en lengua china son mucho más cortas, con un orden fijo para una correcta comprensión y contextualización del discurso. Por el contrario, la lengua española da mucho más sentido a la oración en sí -que puede llegar a ser extremadamente larga y compleja- con abundancia de conjunciones, sin un orden tan fijo y con mayor flexibilidad sintáctica creando una dificultad añadida a los estudiantes chinos. De esta forma podemos señalar que la sintaxis del chino se orienta al discurso, mientras que la del español se orienta a la oración ${ }^{11}$.

Pero la dificultad más interesante por la materia objeto de estudio que no se debe pasar nada por alto es la importancia para la cultura oriental que el texto escrito posee frente al texto oral. El prejuicio cultural donde la palabra escrita tiene mucho más valor que la palabra oral provoca una de las dificultades más evidentes en el ejercicio docente. Este aspecto es el que provoca más reticencias del alumnado con las actividades de expresión oral, de marcado carácter lúdico y desinhibido que las de expresión escrita. Este hándicap debe ser resuelto ya en la primera-segunda sesión de trabajo. El alumnado debe aprender que en el sistema español el teatro juega un papel decisivo en la inmersión cultural, el teatro muestra la vida, costumbres, personajes de épocas determinadas, es un reflejo de la sociedad y puede ser una crítica mordaz. Dentro de la educación obligatoria española muchas son las muestras donde las escuelas reservan ciertas actividades vinculadas al arte (visitas a museos, asistencia a audiciones, a representaciones teatrales) como medio educativo dentro de la educación transversal que se realiza para estudiantes, ya sea de primaria o secundaria. Muchas son las familias españolas que también aprecian el arte como un consumo cultural habitual, es un aprendizaje y tiempo de ocio compartido entre generaciones muy propio de la cultura española en contraposición a la cultura china en la que estas actividades resultan muy específicas únicamente en ciertos colectivos sociales.

En clases se utiliza el juego dramático, con el que se pueden expresar ideas, se puede poner en tela de juicio ciertos dogmas, se pueden tratar temas de diversa índole con nuevas perspectivas. El alumnado oriental es reticente, en un primer momento, a esta libertad y experimentación expresiva, pero con ciertas técnicas de dinámicas de grupo y de improvisación se pueden conseguir resultados ciertamente satisfactorios.

\section{DIDÁCTICA Y METODOLOGÍA APLICADA}

Las características culturales del alumnado sinohablante fruto de esta experiencia son singulares. Como ya se ha comentado en el apartado de dificultades, en primer lugar, la gran mayoría desconoce el arte teatral, no tienen ninguna experiencia previa como participantes y, en segundo lugar, y el más preocupante, que ni tan siquiera han asistido a ninguna representación teatral en su país de origen. Ocasionalmente, según su

$11 \quad$ Ibid., p. 168. 
institución de origen, algún componente ha participado en talleres dirigidos a una representación final, pero estadísticamente menos de un $5 \%$ tiene alguna experiencia teatral, ya sea en su rol actor/actriz o en el rol espectador/a.

Es por este motivo que el reto de la materia supone un doble esfuerzo, ya que - con los 75 alumnos chinos participantes - son escasas las muestras de conocimiento de las disciplinas vinculadas al teatro. Es por este motivo que en la concepción de la asignatura sea obligatoria al menos una visualización de algún espectáculo - a poder ser en vivo y en directo - y la consiguiente explicación de la convención teatral porque la gran mayoría de alumnado necesita un entorno donde entender y enmarcar culturalmente las artes escénicas.

\subsection{Temporalización}

Se estructura una temporalización de 30 sesiones docentes, con una hora de duración. La siguiente distribución $(10+20)$ permite ofrecer al alumnado una inmersión en la materia entendida como trabajo en grupo. Se establecerán vínculos de compañerismo y se mejorará la interrelación del grupo también en otras materias.

Así pues, la materia queda dividida en primer bloque y segundo bloque:

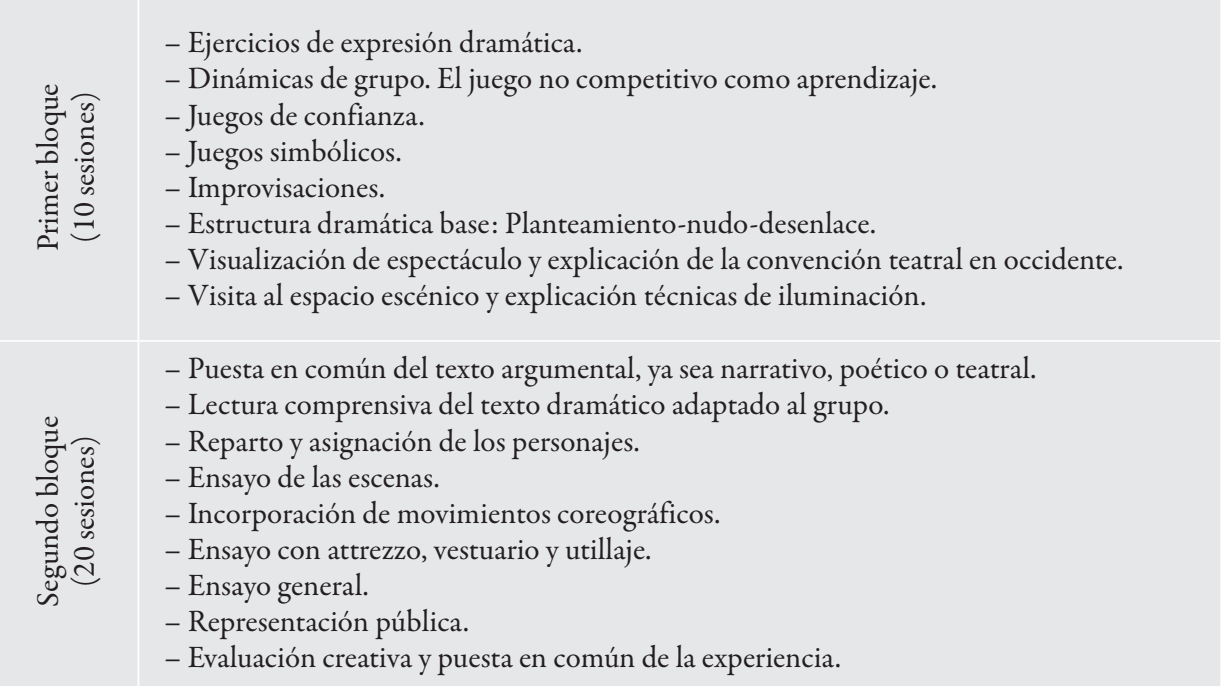

El primer bloque supone el inicio en la cohesión del grupo, observar las características identitarias de cada una de las personas participantes. Se observarán las peculiaridades individuales, la interrelación del grupo, se potencia la confianza del individuo como parte del grupo/clase.

Las primeras sesiones son cruciales para adecuar los objetivos de la materia a la expectativa del alumnado y a las dinámicas de carácter práctico. Se recomienda vestir cómodamente durante las clases y prescindir por completo de teléfonos móviles y de traducciones simultáneas. La inmersión en el trabajo expresivo debe ser total, con el lenguaje verbal y el no verbal. 
El nivel de las improvisaciones varía enormemente de un grupo a otro y también es debido al nivel de conocimiento de español de cada promoción. Efectivamente, cuanto mejor nivel de español posea el grupo, mayor es el aprovechamiento de las habilidades que la técnica de improvisación aporta. Con grupos de niveles de lengua bajos es un aspecto que debe ser cambiado por dramatizaciones guiadas. Ya sea en las improvisaciones como en las dramatizaciones el contenido se basa en la estructura dramática base de planteamiento-nudo y desenlace, que una vez afianzado permite experimentar y jugar con el orden dramático y la secuenciación por escenas. Algunas de las improvisaciones y/o dramatizaciones son recogidas en forma dialogada y en estructura de guion dramático por los alumnos en un trabajo por equipos.

Ejes transversales de aprendizaje como la cultura hispánica, las costumbres, las expresiones informales y coloquiales, surgen de manera fluida y ayudan a mantener un clima idóneo para el trabajo creativo.

El apartado más teórico es la visualización y comentarios sobre espectáculos previamente seleccionados, de manera que se puede apreciar el género teatral, el ritmo, la presencia escénica de los actores y actrices, la puesta en escena y la totalidad de los signos teatrales implicados.

Una clase práctica que aprecian mucho los alumnos son las pruebas de iluminación en el espacio escénico, habitualmente en las instalaciones del Teatro del Escorxador de Lleida, con unos cuantos focos PCs y recortes. La propuesta es actuar siempre notando el foco de luz en la cara, con cambios de posición, distancia y orientación. Esta sesión les sitúa en el punto de mira como actores y actrices, les empodera y su concepción sobre la técnica actoral se amplía.

El segundo bloque de aprendizaje resulta más recurrente en los talleres de teatro, aunque es importante seguir las pautas con el orden propuesto para una buena temporalización del taller, donde puedan darse imprevistos con suficiente margen de corrección. También es importante guardar una sesión para evaluar todo el proceso y resultado final. El aspecto evaluativo utilizado tiene indicadores cualitativos y con feedback directo tanto de los participantes como del público asistente a la función (mayoritariamente profesorado de la universidad, compañeros de piso, parejas lingüísticas y otros alumnos). Una evaluación con parámetros de expresión creativa resulta mucho más útil que encuestas genéricas de perfil académico. En esta asignatura se contempla el trabajo en equipo, las emociones, la gestión de esas emociones, la técnica interpretativa y la respuesta del público.

\subsection{Estructura sesión}

Las sesionen docentes impartidas habitualmente se dividen en 3 apartados ${ }^{12}$ :

- Puesta en marcha. Juego grupal preliminar de calentamiento. Ejercicios motrices o de concentración, de escucha activa que permiten contactar con el 'aquí y el ahora'.

12 Antoni Navarro hace una cuádruple división de las sesiones para una clase o taller en la que en segundo lugar incluye una relajación, pero en esta experiencia no es viable porque rompe el ritmo activo. Consultad "El Taller de Dramatització", Open Course Ware, Universidad de Valencia, [online] http://ocw. uv.es/arts-i-humanitats-1/formacio-literaria-per-a-mestres/el_taller_dramatitzacio.pdf. 
- Actividades de expresión y comunicación. Fase de exploración de la expresión dramática, ya sea por dramatizaciones, improvisaciones, trabajo textual o ensayos.

- Retroacción. Donde se verbaliza el trabajo realizado, los acuerdos pactados y la valoración de la sesión.

\subsection{Metodología}

La metodología utilizada en la impartición de la materia tiene su base en la Pedagogía de la situación ${ }^{13}$. Los postulados de Barret permiten obtener un 'aquí y ahora' siempre cambiante y siempre adecuado a cada grupo, espacio y propuesta. La relación entre la profesora y el grupo también va sujeta a diferentes condicionantes que varían la relación de enseñanza y aprendizaje.

Otra influencia innegable para la impartición de un taller de teatro es la del Dr. Tomás Motos ${ }^{14}$ que con su vasta trayectoria en formación a docentes ha implantado una útil metodología que sirve como referencia marco en todo proceso de enseñanza teatral.

Pero sobre todo la base metodológica es la que dan 20 años de experiencia como formadora de artes escénicas con un estilo autodidacta y ecléctico en la escuela Aula de Teatro donde se priman las necesidades del alumnado y la docencia se entiende como una dinamización del grupo con unos fines concretos. Esto es lo que se denomina 'Método Aula de Teatre'15 fruto de los 30 últimos años de enseñanza de la escuela, con planes de estudio propios tanto para la educación teatral infantil, juvenil, adulta y la profesional.

La profesora ha utilizado diversos roles durante las clases, mayoritariamente ha sido el rol de directora y participante activa. El rol de la profesora varía en función de las necesidades del grupo/clase, habitualmente se inscribe en el rol directora pero también en el participante activo, sobre todo para facilitar cierta imitación cuando la comprensión de la lengua con terminología específica no es total.

Un rol activo permite crear un clima dinámico y de aproximación a los estudiantes. Una vez explicada la propuesta dramática la imitación también ha sido un recurso obvio para ejemplificar el ritmo y la actitud deseada, participar permite el placer de las vivencias compartidas y el ser una pauta a imitar. El rol de directora se ha utilizado más en el segundo bloque de aprendizaje, cuando el texto ya se intenta poner en escena y es el alumnado quien propone su personaje particular durante los ensayos. La visión global

13 G. Barret, Pedagogía de la expresión dramática, trad. M. Larrañaga, R. Odriozola, Montreal 1989.

14 Director del Máster en Teatro Aplicado en la Universidad de Valencia donde ha ejercido como profesor de Psicopedagogía de la Dramatización, Teatro del Oprimido y Evaluación y Reflexión de las Prácticas Escénicas. Autor de más de una veintena de libros, capítulos de libros y materiales didácticos sobre Didáctica de la Dramatización-Teatro, Expresión corporal, Creatividad, Didáctica de la Lengua y la Literatura y Teatro Aplicado.

15 El concretar en una publicación el 'Método Aula de Teatre' aún es una asignatura pendiente pero no así en su implantación práctica en gran parte de los docentes que se retroalimentan de este método que aporta una calidad de aprendizaje teatral de manera lúdica, transversal y con valores que afianzan al alumnado su crecimiento personal integral. 
de dirección permite acotar el lenguaje expresivo, pautar ritmos, entradas, salidas e interacciones entre las escenas. La visión del rol directora es, indiscutiblemente, el más técnico y adecuado para el taller.

Aunando las tres líneas metodológicas (Barret-Motos-Aula de Teatre) la asignatura impartida responde a un método propio, permeable siempre a propuestas de mejora y con un estilo muy personal de la docente ${ }^{16}$.

El taller de teatro parece ser el objetivo de la materia y no el estudio gramatical, cultural o académico en sí. Permite al alumnado crear textos en grupo, improvisar, consensuar, corregir y ensayar para un fin común. Este hecho permite un divertimento que multiplica la aplicación práctica de la lengua de manera lúdica y distendida. Es un aprendizaje creativo que se consigue mediante técnicas propias del juego dramático.

\section{RESULTADOS Y CONCLUSIONES}

En general el buen resultado de un aprendizaje por medio de la expresión dramática viene avalado por numerosos estudios y proyectos que actualmente se están realizando en el entorno escolar. Así las experiencias teatrales:

Están concebidas no solo para ver y disfrutar el teatro, sino para compartir herramientas útiles en la creación innovadora de situaciones de aprendizaje, tanto en el teatro como en la escuela, destacando las variables de la pedagogía de la situación ${ }^{17}$.

En particular también muchos han sido los resultados satisfactorios en implantar la expresión dramática en el aprendizaje del español para extranjeros ya que las dramatizaciones constituyen ventajas reales para adquirir una $E L E^{18}$.

A modo concluyente se relacionan los resultados concretos que esta experiencia de 4 cursos académicos ha aportado a sus partes integrantes:

Para las instituciones implicadas (DEH-UdL-Aula Municipal de Teatro):

- Consolidación de la asignatura.

- Prórroga del convenio de colaboración.

16 Con cerca de 20 años de experiencia docente en el ámbito de las artes escénicas me embarqué en este reto como un curso más, específico para el aprendizaje de la lengua y cultura española por medio del teatro. Al final de la primera clase entendí que las habilidades comunicativas que siempre habían funcionado no eran útiles para el grupo. Mis alumnos no comprendían ni un 30\% de mis explicaciones y lo que era más problemático, disimulaban su falta de comprensión. Quise contrastar esta información con la coordinadora del DEH quién corroboró mi hipótesis inicial y me dio su apoyo para las tareas docentes en este tipo de alumnado procedente de una cultura donde el respeto por el profesor impide cualquier duda o pregunta directa y la expresión artística no está en absoluto integrada ni en la educación ni en la sociedad. Detectado el problema inicial mi estrategia docente se centró en explicaciones mucho más cortas y de contraste práctico inmediato. Muchas de las dinámicas propuestas fueron de ejercicios de acción-reacción y así podía entrever fácilmente el grado de aprendizaje del alumnado.

17 A. Tresserras et al., "Pedagogía de la situación: expresión dramática en la escuela", Revista de Investigación en Educación, vol 12, no. 2 (2014), pp. 231-232, [online] http://reined.webs.uvigo.es/index.php/ reined/article/view/259.

18 J. Renaudin, "La improvisación dramática como entrenamiento estratégico en el aula de LE", MarcoELE. Revista de Didáctica Español Lengua Extranjera, no. 14 (2012), p. 6. 
- Visibilidad de los estudios hispánicos en el ámbito artístico y viceversa.

- Realización de 4 talleres teatrales con presentación pública en el Teatro del Escorxador de Lleida.

- Visibilidad en las redes de los resultados escénicos ${ }^{19}$.

- Confirmación del respeto y empatía entre las culturas china e hispánica. Para el alumnado sinohablante:

- Enriquecimiento cultural.

- Desarrollo de ejes transversales en el aprendizaje de la lengua y la cultura hispánica.

- Empoderamiento y crecimiento personal.

- Mejora de la comunicación verbal y no verbal.

- Aprendizaje práctico de habilidades comunicativas por medio de técnicas dramáticas.

- Asimilación más fluida del lenguaje, registros lingüísticos y expresiones.

- Mejora de las habilidades interpersonales, interculturales y sociales

- Estímulo del sentido de la iniciativa y el emprendimiento.

- Gusto por las actividades expresivas y escénicas.

- Afianzamiento del trabajo en equipo respetando las individualidades.

Delante de los resultados obtenidos la coordinadora de la actividad, la Sra Olga Fransi y el impulsor del DEH, el Dr. Javier Terrado, propusieron dejar entrever una presentación en público ya en el primer trimestre/cuatrimestre del curso con el fin de beneficiar al resto de asignaturas de la unión del grupo y del trabajo en equipo que se generan mediante la puesta en escena conjunta. De manera que en el transcurso de esta experiencia docente se ha dado una evolución y adecuación de los contenidos ya que en los dos últimos cursos académicos se acentuó más el proceso, con lo que hay dos presentaciones públicas anuales. La primera en el primer trimestre-cuatrimestre y la segunda al final. De esta forma se modificó la temporalización general del curso bajo las directrices del nuevo objetivo con dos presentaciones públicas, la primera de creación propia, a partir de improvisaciones de los alumnos y la segunda de teatro textual con creación de personajes alejados de su realidad.

Sin obviar las dificultades que supone el aprendizaje de ELE a los estudiantes sinohablantes el reto añadido del aprendizaje creativo por medio de técnicas expresivas no hace sino enriquecer su percepción global de la lengua y cultura hispánica y acercarse más a la realidad.

Como conclusión, cabe reafirmar que la expresión dramática es un instrumento útil para el aprendizaje de estudios hispánicos en estudiantes sinohablantes. Ante los resultados comparativos destaca el cambio y la transformación en el clima del grupo-clase con el objetivo final del taller de teatro para favorecer habilidades comunicativas y sociales de todos sus componentes y, especialmente, la satisfacción expresada por exalumnos que recuerdan muy positivamente su aprendizaje con la metodología propia de la expresión dramática.

19 Se ofrecen más de 400 imágenes de libre consulta en https://www.flickr.com/photos/132949201@ N04/albums/page1/. 


\section{BIBLIOGRAFÍA}

IV Semana de las Letras Hispanicas, Universidad de Lleida, 27 marzo 2019, [online] http:// www.filcef.udl.cat/es/activitats/pagina-1, 20 diciembre 2019.

Aula Lleida’s album, Flickr, [online] https://www.flickr.com/photos/132949201@N04/albums/page1, 20 diciembre 2019.

Aula, 25 anys, Aula de Teatre de Lleida, 2007.

Barret G., Pedagogía de la expresión dramática, trad. M. Larrañaga, R. Odriozola, Montreal 1989.

Boal A., Teatro del Oprimido, Barcelona 2009.

Educational Drama, Drama Improves Lisbon Key Competences in Education, [online] http:// www.dramanetwork.eu/educational_drama.html, 18 enero 2020.

El Diploma de Estudios Hispánicos, Universidad de Lleida, 25 julio 2019, [online] http://www. filcef.udl.cat/es/estudis/diploma-destudis-hispanics/, 20 diciembre 2018.

Galceran J., El mètode Grönholm, Barcelona, 2003.

Hidalgo V., "Actividades dramáticas en la clase de ELE", [online] https://cvc.cervantes.es/ensenanza/biblioteca_ele/publicaciones_centros/PDF/budapest_2013/48_hidalgo.pdf, 8 marzo 2018.

História i tradició, Universidad de Lleida, 26 juny 2019, [online] http://www.udl.es/ca/udl/ historia, 20 diciembre 2019.

Laferrière G., “Teatro y educación o el arte de la seducción”, Ñaque, no. 29 (2003), [online] http://www.naque.es/revistas/pdf/R29.pdf, 1 marzo 2018.

Llorens M.J., Leyendas Españolas, Madrid 1998.

Motos T., "Psicopedagogía de la dramatización”,2013, [online] http://www.postgradoteatroeducacion.com/wp-content/uploads/2013/11/Piscopedagogia-de-la-dramatizaci\%C3\%B3nTom\%C3\%A1s-Motos.pdf, 1 marzo 2018.

Navarro A., "El Taller de Dramatització", Open Course Ware, Universidad de Valencia, [online] http://ocw.uv.es/arts-i-humanitats-1/formacio-literaria-per-a-mestres/el_taller_dramatitzacio.pdf, 18 de enero 2020.

Perelló R., Les Escoles Municipals de Lleida (1979-1994), Lleida 1995.

Renaudin J., "La improvisación dramática como entrenamiento estratégico en el aula de LE", MarcoELE. Revista de Didáctica Español Lengua Extranjera, no. 14 (2012).

Sánchez Griñán A., "Estrategias de aprendizaje de ELE de sinohablantes (comprensión) y para sinohablantes (instrucción): un proyecto abierto", SinoELE, vol. 1 (2009).

Santos Rovira J.M., "Dificultades específicas de los sinohablantes aprendices de español", Estudios de Lingüistica Aplicada, vol. 29, no. 54 (2011), https://doi.org/10.22201/ enallt.01852647p.2011.54.490.

Tejerina I., "El juego dramático como herramienta de la educación intercultural”, Primeras noticias. Revista de literatura, no. 244 (2009).

Tresserras A. et al., "Pedagogía de la situación: expresión dramática en la escuela”, Revista de Investigación en Educación, vol. 12, no. 2 (2014), [online] http://reined.webs.uvigo.es/index. $\mathrm{php} / \mathrm{reined} /$ article/view/259, 17 diciembre 2019. 
U-Ranking de las universidades españolas, [online] http://www.u-ranking.es/analisis.php, 20 diciembre 2019.

Yousefian S., "El teatro en la clase de ELE", Revista Nebrija de Linguística Aplicada a la Enseñanza de las Lenguas, no. 13 (2013), [online] http://www.nebrija.com/revista-linguistica/ el-teatro-en-la-clase-de-ele, 15 febrero 2018.

Mercè BALLESPÍ VILLAGRASA - profesora, directora escénica e investigadora. Ha formado parte del grupo de investigación GRAE de la UAB y del comité de expertos para la elaboración del ciclo formativo de grado superior especializado en técnicas teatrales para la Generalitat de Cataluña. Ha sido Directora del Aula Municipal de Teatro de Lleida y del Ciclo Formativo de Grado superior de Técnicas de Actuación Teatral. Profesora de la asignatura Teatro y expresividad para el Diploma de Estudios Hispánicos(DEH) en la Universidad de Lleida con alumnado chino. Actualmente también es docente de Lengua castellana y Literatura y Artes Escénicas en el INS Samuel Gili Gaya. Como investigadora teatral ha publicado diversos artículos en libros y revistas especializadas, centrándose en la relación entre la praxis escénica con la enseñanza teatral, la perspectiva de género y las dramaturgias contemporáneas, textuales y no textuales. 